\title{
Upaya Meningkatkan Kompetensi Guru dalam Menyusun Silabus melalui Bimbingan dan Supervisi di SD Negeri 1 Kalinanas
}

\author{
S Rusmiyati* \\ ${ }^{1}$ SDN 1Kalinanas, Japah, Blora. Dinas Pendidikan Kabupaten Blora Propinsi Jawa \\ Tengah. Desa Kalinanas Kecamatan Japah Kabupaten Blora 58257, Indonesia \\ *srirusmiyati0@gmail.com
}

\begin{abstract}
The purpose of this study is to improve the competence of teachers in SD Negeri 1 Kalinanas in compiling learning syllabus documents. The study was conducted at SD Negeri 1 Kalinanas for \pm 5 months starting July 2015 to December 2015. The number of teachers in SD Negeri 1 Kalinanas who attended Guidance and Supervision amounted to 9 teachers. Data collection is done through interviews, observation and documentation. From the interview, the results showed that overall the teachers at SD Negeri 1 Kalinanas stated that it was important to prepare the learning syllabus documents very well. The study was conducted in 2 cycles. In the pre cycle, the average value of 77 was obtained with a percentage of $52 \%$ achievement of all teachers in the syllabus preparation research indicator. In cycle 1 the average value was 84 with $67 \%$ achievement of all teachers in the syllabus preparation research indicators, and the second cycle on average 98 with a $95 \%$ percentage of achievement of all teachers in the syllabus preparation research indicators. There was an increase in teacher competency in the preparation of syllabus after Guidance and Supervision were carried out by the principal of SD 1 Kalinanas.
\end{abstract}

Abstrak. Tujuan penelitian ini adalah untuk meningkatkan kompetensi guru di SD Negeri 1 Kalinanas dalam menyusun dokumen silabus pembelajaran. Penelitian dilakukan di SD Negeri 1 Kalinanas selama \pm 5 bulan dimulai Juli 2015 sampai dengan Desember 2015. Jumlah guru di SD Negeri 1 Kalinanas yang mengikuti Bimbingan dan Supervisi berjumlah 9 guru. Pengumpulan data dilakukan melalui wawancara, observasi dan dokumentasi. Dari wawancara diperoleh hasil bahwa secara keseluruhan guru di SD Negeri 1 Kalinanas menyatakan penting untuk menyusun dokumen silabus pembelajaran dengan sangat baik. Penelitian dilakukan sebanyak 2 siklus. Pada pra siklus diperoleh nilai rata-rata 77 dengan persentase $52 \%$ pencapaian seluruh guru dalam indikator penelitian penyusunan silabus, pada siklus 1 diperoleh nilai rata-rata 84 dengan persentase $67 \%$ pencapaian seluruh guru dalam indikator penelitian penyusunan silabus, dan pada siklus II diperoleh nilai rata-rata 98 dengan persentase $95 \%$ pencapaian seluruh guru dalam indikator penelitian penyusunan silabus. Terjadi peningkatan kompetensi guru dalam penyusunan silabus setelah dilakukan Bimbingan dan Supervisi oleh kepala sekolah SD Negeri 1 Kalinanas.

Kata kunci: silabus pembelajaran, kompetensi guru, Bimbingan dan Supervisi

\section{Pendahuluan}

Pendidik yang profesional bukan hanya mampu mendidik peserta didiknya dengan baik tetapi juga secara administrasi baik yaitu perencanaan programnya. Tiga kompetensi dasar yang harus dimiliki guru, yakni: (1) menguasai materi atau bahan ajar, (2) antusiasme, dan (3) penuh kasih sayang (loving) dalam mengajar dan mendidik [1]. Perencanaan program berfungsi untuk memberikan arah pelaksanaan pembelajaran sehingga menjadi terarah dan efisien. Salah satu bagian dari perencanaan pembelajaran yang sangat penting dibuat oleh guru sebagai pengarah 
pembelajaran adalah silabus dan Rencana Pelaksanaan Pembelajaran (RPP). Silabus memberikan arah tentang apa saja yang harus dicapai guna menggapai tujuan pembelajaran dan cara seperti apa yang akan digunakan. Selain itu silabus juga memuat teknik penilaian seperti apa untuk menguji sejauh mana keberhasilan pembelajaran. Dengan melihat pentingnya penyusunan perencanaan pembelajaran ini, guru semestinya tidak mengajar tanpa adanya rencana.

Namun sayang perencanaan pembelajaran yang mestinya dapat diukur oleh kepala sekolah ini, tidak dapatdiukur oleh kepala sekolah karena hanya direncanakan dalam pikiran sang guru saja. Akibatnya kepala sekolah sebagai pembuat kebijakan di sekolah tidak dapat mengevaluasi kinerja guru secara akademik. Kinerja yang dapat dilihat oleh kepala sekolah hanyalah kehadiran tatap muka, tanpa mengetahui apakah kompetensi guru dalam mengelola pembelajaran sudah sesuai dengan harapan atau belum, atau sudahkah kompetensi dasar yang harus dikuasai oleh peserta didik terkuasai dengan benar.

Berdasarkan hasil penelitian pra siklus melalui bimbingan dan supervisi yang dilakukan di SD Negeri I Kalinanas Kecamatan Japah Kabupaten Blora diperoleh hasil terhadap Silabus Pembelajaran dengan indikator yaitu 1) Standar Kompetensi sebesar 56\%, 2) Kompetensi Dasar sebesar 56\%, 3) Hasil Belajar sebesar 56\%, 4) Indikator sebesar 56\%, 5) Materi pokok sebesar $56 \%, 6$ ) Kegiatan Pembelajaran sebesar 56\%, 7) Alokasi waktu sebesar 44\%, 8) Penilaian sebesar $44 \%$, dan 9) Sumber/sarana belajar sebesar $44 \%$.

Bertolak dari pemsalahan tersebut diperlukan alternatif solusi Untuk menyelesaikan masalah tersebut. perlu diadakan supervisi atau pembinaan terhadap guru secara terus menerus untuk meningkatkan kinerjanya. Frank Parson. Bimbingan sebagai bantuan yang diberikan kepada individu untuk dapat memilih, mempersiapkan diri dan memangku suatu jabatan dan mendapat kemajuan dalam jabatan yang dipilihnya. Bimbingan membantu individu untuk lebih mengenal berbagai informasi tentang dirinya sendiri.

Bimbingan dilakukan untuk meningkatkan perwujudan diri individu." Dapat dipahami bahwa bimbingan membantu individu untuk mengaktualisasikan diri dengan lingkungannya. Bimbingan adalah petunjuk penjelasan cara mengerjakan sesuatu, tuntutan [4]. Kinerja guru perlu ditingkatkan agar usaha membimbing peserta didik untuk belajar dapat berkembang. Tingkat produktivitas sekolah dalam memberikan pelayanan-pelayanan secara efisien kepada pengguna ( peserta didik, masyarakat ) akan sangat tergantung pada kualitas gurunya yang terlibat langsung dalam proses pembelajaran dan keefektifan mereka dalam melaksanakan tanggung jawab individual dan kelompok. Hal ini berarti bahwa guru sebagai fasilitator yang mengelola proses pembelajaran di kelas mempunyai andil dalam menentukan kualitas pendidikan. Konsekuensinya adalah guru harus mempersiapkan ( merencanakan) segala sesuatu agar proses pembelajaran di kelas berjalan dengan efektif.

Selanjutnya upaya yang dapat dilakukan adalah dengan pengadaan supervisi oleh kepala sekolah. Konsep supervisi modern sebagai berikut: "Supervision is assistance in the devolepment of a better teaching learning situation". Supervisi adalah bantuan dalam pengembangan situasi pembelajaran yang lebih baik. Rumusan ini mengisyaratkan bahwa layanan supervisi meliputi keseluruhan situasi belajar mengajar (goal, material, technique, method, teacher, student, an envirovment). Situasi belajar inilah yang seharusnya diperbaiki dan ditingkatkan melalui layanan kegiatan supervisi. Dengan demikian layanan supervisi tersebut mencakup seluruh aspek dari penyelenggaraan pendidikan dan pengajaran [2].

Supervisi sebagai berikut: "Pembinaan yang diberikan kepada seluruh staf sekolah agar mereka dapat meningkatkan kemampuan untuk mengembangkan situasi belajar mengajar yang lebih baik". Dengan demikian, supervisi ditujukan kepada penciptaan atau pengembangan situasi belajar mengajar yang lebih baik. Untuk itu ada dua hal (aspek) yang perlu diperhatikan : Pelaksanaan kegiatan belajar mengajar dan hal-hal yang menunjang kegiatan belajar mengajar [1].

Berdasarkan latar belakang tersebut di atas maka dirumuskan permasalahan yaitu apakah dengan bimbingan dan supervisi akan dapat meningkatkan kompetensi guru dalam menyusun Silabus Pembelajaran di SD Negeri I Kalinanas Kecamatan Japah Kabupaten Blora tahun pelajaran 2016/2017? Tujuan dari penelitian ini adalah untuk meningkatkan kompetensi guru dalam menyusun Silabus Pembelajaran melalui bimbingan dan supervisi di SD Negeri I Kalinanas Kecamatan Japah Kabupaten Blora tahun pelajaran 2016/2017. 


\section{Metode}

Metode yang digunakan dalam penelitian ini adalah metode deskriptif, dengan menyusun teknik persentase untuk melihat peningkatan yang terjadi dari siklus ke siklus Penelitian ini adalah penelitian tindakan sekolah yang dilaksanakan dalam 2 siklus. Dengan tahapan perencanaan, pelaksanaan, observasi dan refleksi. Yang menjadi subyek dalam PTS ini adalah guru-guru di SD Negeri I Kalinanas Kecamatan Japah Kabupaten Blora yang berjumlah 9 guru termasuk guru kelas dan guru mata pelajaran. Sumber data dalam PTS ini adalah dokumen Silabus Pembelajaran yang sudah dibuat guru yang yang memuat indikator : 1) Standar Kompetensi 2) Kompetensi Dasar 3) Hasil Belajar 4) Indikator 5) Materi pokok 6) Kegiatan Pembelajaran 7) Alokasi waktu 8) Penilaian dan 9) Sumber/sarana belajar. Teknik pengumpulan data dalam penelitian ini adalah wawancara, observasi, dan diskusi.

\section{Hasil dan Pembahasan}

Hasil penelitian ini menunjukkan peningkatan pada setiap siklusnya. Data diperoleh dari nilai peningkatan kompetensi guru dalam menyusun silabus.

Tabel 1.Daftar Nilai Peningkatan Kompetensi guru Dalam Menyusun Silabus Pembelajaran Sebelum Tindakan (Pra siklus)

NAMA RESPONDEN

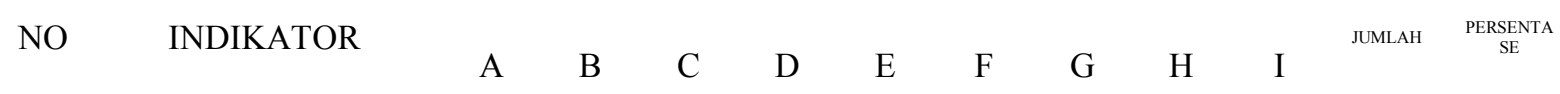

\begin{tabular}{|c|c|c|c|c|c|c|c|c|c|c|c|c|}
\hline 1 & $\begin{array}{l}\text { Mencantumkan } \\
\text { Standar Kompetensi }\end{array}$ & 4 & 4 & 4 & 4 & 4 & 2 & 3 & 2 & 1 & 28 & $77 \%$ \\
\hline 2 & $\begin{array}{l}\text { Mencantumkan } \\
\text { Kompetensi Dasar }\end{array}$ & 4 & 3 & 4 & 2 & 3 & 4 & 4 & 4 & 2 & 30 & $83 \%$ \\
\hline 3 & $\begin{array}{l}\text { Mencantumkan } \\
\text { Kompetensi Dasar }\end{array}$ & 4 & 4 & 4 & 4 & 4 & 2 & 1 & 2 & 3 & 28 & $77 \%$ \\
\hline 4 & $\begin{array}{l}\text { Mencantumkan Hasil } \\
\text { Belajar }\end{array}$ & 2 & 4 & 2 & 4 & 3 & 4 & 4 & 2 & 4 & 29 & $80 \%$ \\
\hline 5 & $\begin{array}{l}\text { Mencantumkan } \\
\text { Indikator Belajar }\end{array}$ & 4 & 4 & 2 & 3 & 4 & 1 & 4 & 4 & 2 & 28 & $77 \%$ \\
\hline 6 & $\begin{array}{l}\text { Mencantumkan Materi } \\
\text { Pokok Pembelajaran }\end{array}$ & 2 & 2 & 4 & 1 & 4 & 4 & 2 & 4 & 4 & 27 & $75 \%$ \\
\hline 7 & $\begin{array}{l}\text { Mencantumkan } \\
\text { Alokasi Waktu } \\
\text { Pembelajaran }\end{array}$ & 4 & 4 & 3 & 4 & 2 & 2 & 4 & 1 & 1 & 25 & $69 \%$ \\
\hline 8 & $\begin{array}{l}\text { Mencantumkan } \\
\text { Penilaian } \\
\text { Pembelajaran }\end{array}$ & 4 & 2 & 4 & 3 & 4 & 3 & 2 & 4 & 2 & 28 & $77 \%$ \\
\hline 9 & $\begin{array}{l}\text { Mencantumkan } \\
\text { Sumber dan Sarana } \\
\text { Pembelajaran } \\
\end{array}$ & 3 & 4 & 3 & 4 & 2 & 4 & 1 & 2 & 4 & 27 & $75 \%$ \\
\hline & JUMLAH & 31 & 31 & 30 & 29 & 30 & 26 & 25 & 25 & 23 & & \\
\hline & NILAI & 86 & 86 & 83 & 81 & 83 & 72 & 69 & 69 & 64 & 77 & $52 \%$ \\
\hline & KETERANGAN & $\mathrm{M}$ & $\mathrm{M}$ & $\mathrm{M}$ & $\mathrm{M}$ & M & $\mathrm{BM}$ & $\mathrm{BM}$ & $\mathrm{BM}$ & $\mathrm{BM}$ & & \\
\hline
\end{tabular}




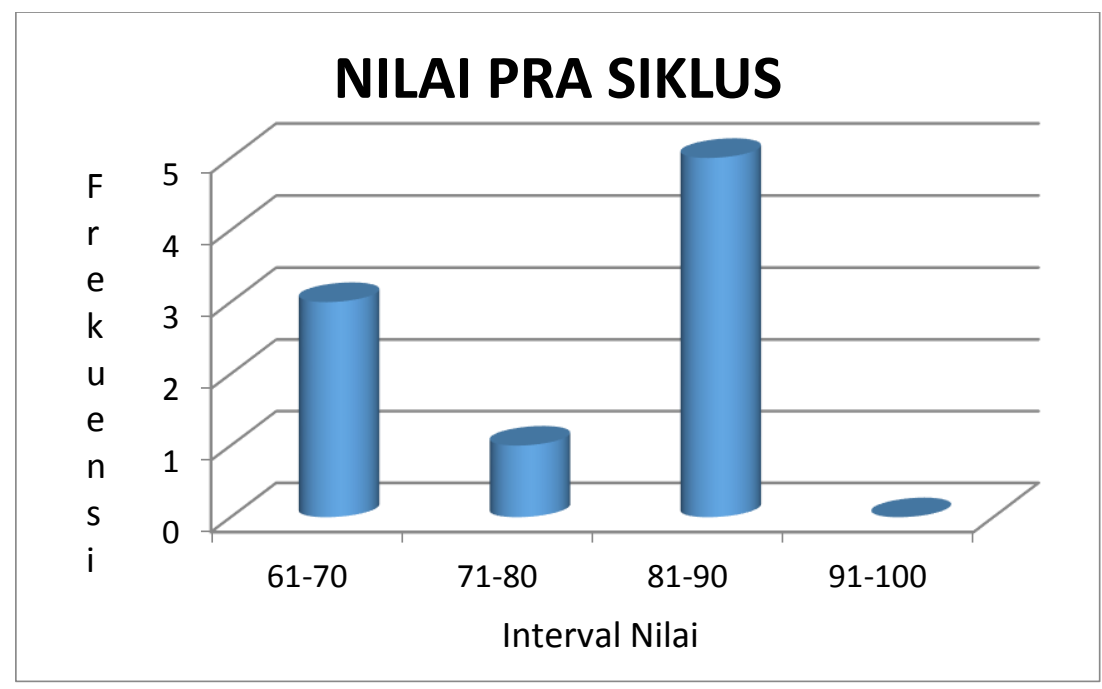

Gambar 1. Grafik Nilai Peningkatan Kompetensi guru Dalam Menyusun Silabus Pembelajaran Sebelum Tindakan (Pra Siklus)

Dari tabel di atas dapat dilihat bahwa penilaian peningkatan kompetensi guru dalam menyusun Silabus Pembelajaran yang dilakukan sebelum pelaksanaan siklus (pra siklus) diketahui bahwa hasilnya masih sangat rendah terbukti dari data perolehan di atas. Data perolehan nilai komepetensi guru pada siklus 1 dapat dilihat pada tabel berikut.

Tabel 2. Daftar Nilai Peningkatan Kompetensi guru Dalam Menyusun Silabus Pembelajaran Siklus 1

$$
\text { NAMA RESPONDEN }
$$

$\begin{array}{lllllllllllll}\text { NO INDIKATOR } & \text { A } & \text { B } & \text { C } & \text { D } & \text { E } & \text { F } & \text { G } & \text { H } & \text { I } & \text { LAH } & \text { PERSENTASE }\end{array}$

\begin{tabular}{|c|c|c|c|c|c|c|c|c|c|c|c|c|}
\hline 1 & $\begin{array}{l}\text { Mencantumkan } \\
\text { Standar Kompetensi }\end{array}$ & 4 & 4 & 4 & 4 & 4 & 4 & 4 & 2 & 2 & 32 & $\begin{array}{l}78 \\
\% \\
\end{array}$ \\
\hline 2 & $\begin{array}{l}\text { Mencantumkan } \\
\text { Kompetensi Dasar }\end{array}$ & 4 & 4 & 4 & 2 & 4 & 4 & 4 & 4 & 2 & 32 & $\begin{array}{l}78 \\
\% \\
\end{array}$ \\
\hline 3 & $\begin{array}{l}\text { Mencantumkan } \\
\text { Kompetensi Dasar }\end{array}$ & 4 & 4 & 4 & 4 & 4 & 4 & 2 & 3 & 4 & 33 & $\begin{array}{l}78 \\
\%\end{array}$ \\
\hline 4 & $\begin{array}{l}\text { Mencantumkan Hasil } \\
\text { Belajar }\end{array}$ & 2 & 4 & 2 & 4 & 4 & 4 & 4 & 2 & 4 & 30 & $\begin{array}{l}67 \\
\% \\
\end{array}$ \\
\hline 5 & $\begin{array}{l}\text { Mencantumkan } \\
\text { Indikator Belajar }\end{array}$ & 4 & 4 & 2 & 4 & 4 & 2 & 4 & 4 & 2 & 30 & $\begin{array}{l}67 \\
\% \\
\end{array}$ \\
\hline 6 & $\begin{array}{l}\text { Mencantumkan Materi } \\
\text { Pokok Pembelajaran }\end{array}$ & 4 & 2 & 4 & 2 & 4 & 4 & 2 & 4 & 4 & 30 & $\begin{array}{l}67 \\
\% \\
\end{array}$ \\
\hline 7 & $\begin{array}{l}\text { Mencantumkan } \\
\text { Alokasi Waktu } \\
\text { Pembelajaran }\end{array}$ & 4 & 4 & 4 & 4 & 2 & 3 & 4 & 1 & 1 & 27 & $\begin{array}{l}56 \\
\%\end{array}$ \\
\hline 8 & $\begin{array}{l}\text { Mencantumkan } \\
\text { Penilaian } \\
\text { Pembelajaran }\end{array}$ & 4 & 2 & 4 & 4 & 4 & 3 & 2 & 4 & 2 & 29 & $\begin{array}{l}56 \\
\%\end{array}$ \\
\hline 9 & $\begin{array}{l}\text { Mencantumkan } \\
\text { Sumber dan Sarana } \\
\text { Pembelajaran }\end{array}$ & 3 & 4 & 4 & 4 & 2 & 4 & 2 & 2 & 4 & 29 & $\begin{array}{l}56 \\
\%\end{array}$ \\
\hline & JUMLAH & 33 & 32 & 32 & 32 & 32 & 32 & 28 & 26 & 25 & & \\
\hline & NILAI & 92 & 89 & 89 & 89 & 89 & 89 & 78 & 72 & 69 & 84 & $\begin{array}{l}67 \\
\% \\
\end{array}$ \\
\hline & KETERANGAN & $\mathrm{M}$ & $\mathrm{M}$ & $\mathrm{M}$ & $\mathrm{M}$ & $\mathrm{M}$ & $\mathrm{M}$ & $\mathrm{M}$ & $\mathrm{BM}$ & $\mathrm{BM}$ & & \\
\hline
\end{tabular}




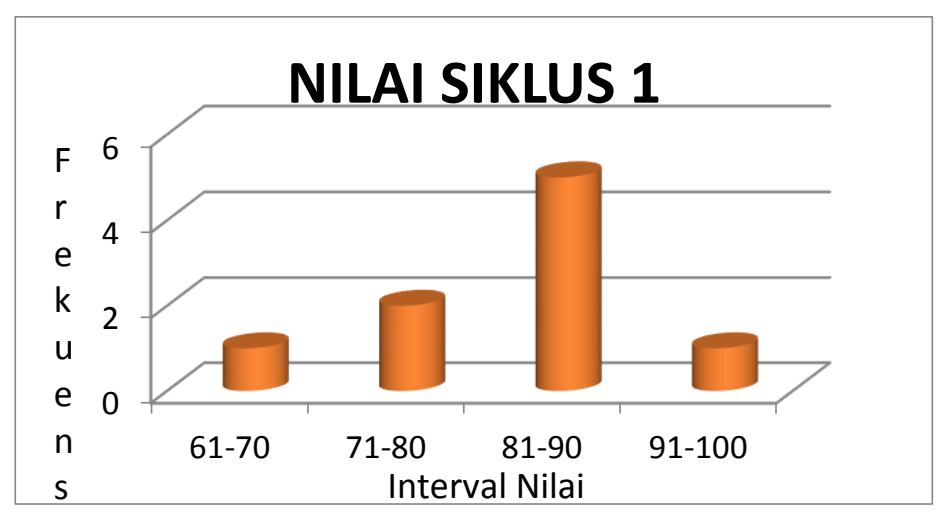

Gambar 2.Grafik Nilai Peningkatan Kompetensi guru Dalam

Menyusun Silabus Pembelajaran Siklus 1

Berdasarkan data yang diperoleh pada siklus 1 dapat dikatakan bahwa terjadi peningkatan untuk masing-masing indikator penelitian dari kegiatan pra siklus ke siklus 1 . Dan dari hasil penilaian yang dilakukan diperoleh data rata-rata prosentase untuk semua indikator Silabus Pembelajaran adalah $69 \%$ dan rata-rata hasil nilai guru adalah 84 . Untuk nilai yang diperoleh setiap responden sudah baik yaitu diatas nilai 75 , tetapi untuk perolehan nilai pada masing-masing indikator penilaian terdapat beberapa indikator yang belum mencapai target atau indikator keberhasilan sebesar $75 \%$. Maka dari itu dilakukan penelitian lagi dengan tahap yang sama seperti pada siklus 1 yang akan dilakukan pada siklus II sehingga semua indikator dapat tercapai sesuai dengan indikator keberhasilan. Selanjutnya pada siklus 2 diperoleh data sebagai berikut.

Tabel 3. Daftar Nilai Peningkatan Kompetensi guru Dalam Menyusun Silabus Pembelajaran Siklus II

\begin{tabular}{|c|c|c|c|c|c|c|c|c|c|c|c|c|}
\hline \multirow[b]{2}{*}{ NO } & \multirow[b]{2}{*}{ INDIKATOR } & \multicolumn{9}{|c|}{ NAMA RESPONDEN } & \multirow[b]{2}{*}{ JUMLAH } & \multirow[b]{2}{*}{$\begin{array}{l}\text { PERSE } \\
\text { NTASE }\end{array}$} \\
\hline & & A & B & $\mathrm{C}$ & $\mathrm{D}$ & $\mathrm{E}$ & $\mathrm{F}$ & G & $\mathrm{H}$ & I & & \\
\hline 1 & $\begin{array}{l}\text { Mencantumkan } \\
\text { Standar Kompetensi }\end{array}$ & 4 & 4 & 4 & 4 & 4 & 4 & 4 & 4 & 4 & 36 & $\begin{array}{c}100 \\
\%\end{array}$ \\
\hline 2 & $\begin{array}{l}\text { Mencantumkan } \\
\text { Kompetensi Dasar }\end{array}$ & 4 & 4 & 4 & 4 & 4 & 4 & 4 & 4 & 4 & 36 & $\begin{array}{c}100 \\
\%\end{array}$ \\
\hline 3 & $\begin{array}{l}\text { Mencantumkan } \\
\text { Kompetensi Dasar }\end{array}$ & 4 & 4 & 4 & 4 & 4 & 4 & 4 & 4 & 4 & 36 & $\begin{array}{c}100 \\
\%\end{array}$ \\
\hline 4 & $\begin{array}{l}\text { Mencantumkan Hasil } \\
\text { Belajar }\end{array}$ & 4 & 4 & 4 & 4 & 4 & 4 & 4 & 4 & 4 & 36 & $\begin{array}{c}100 \\
\%\end{array}$ \\
\hline 5 & $\begin{array}{l}\text { Mencantumkan } \\
\text { Indikator Belajar }\end{array}$ & 4 & 4 & 4 & 4 & 4 & 4 & 4 & 4 & 4 & 36 & $\begin{array}{c}100 \\
\%\end{array}$ \\
\hline 6 & $\begin{array}{l}\text { Mencantumkan Materi } \\
\text { Pokok Pembelajaran }\end{array}$ & 4 & 4 & 4 & 4 & 4 & 4 & 3 & 4 & 4 & 35 & $89 \%$ \\
\hline 7 & $\begin{array}{l}\text { Mencantumkan } \\
\text { Alokasi Waktu } \\
\text { Pembelajaran }\end{array}$ & 4 & 4 & 4 & 4 & 4 & 4 & 4 & 4 & 2 & 34 & $89 \%$ \\
\hline 8 & $\begin{array}{l}\text { Mencantumkan } \\
\text { Penilaian } \\
\text { Pembelajaran }\end{array}$ & 4 & 4 & 4 & 4 & 4 & 4 & 4 & 4 & 2 & 34 & $89 \%$ \\
\hline 9 & $\begin{array}{l}\text { Mencantumkan } \\
\text { Sumber dan Sarana } \\
\text { Pembelajaran }\end{array}$ & 4 & 4 & 4 & 4 & 4 & 4 & 4 & 2 & 4 & 34 & $89 \%$ \\
\hline & JUMLAH & 36 & 36 & 36 & 36 & 36 & 36 & 35 & 34 & 32 & & \\
\hline & NILAI & 100 & 100 & 100 & 100 & 100 & 100 & 97 & 94 & 89 & 98 & $95 \%$ \\
\hline & KETERANGAN & $\mathrm{M}$ & $\mathrm{M}$ & $\mathrm{M}$ & $\mathrm{M}$ & M & $\mathrm{M}$ & M & $\mathrm{M}$ & M & & \\
\hline
\end{tabular}




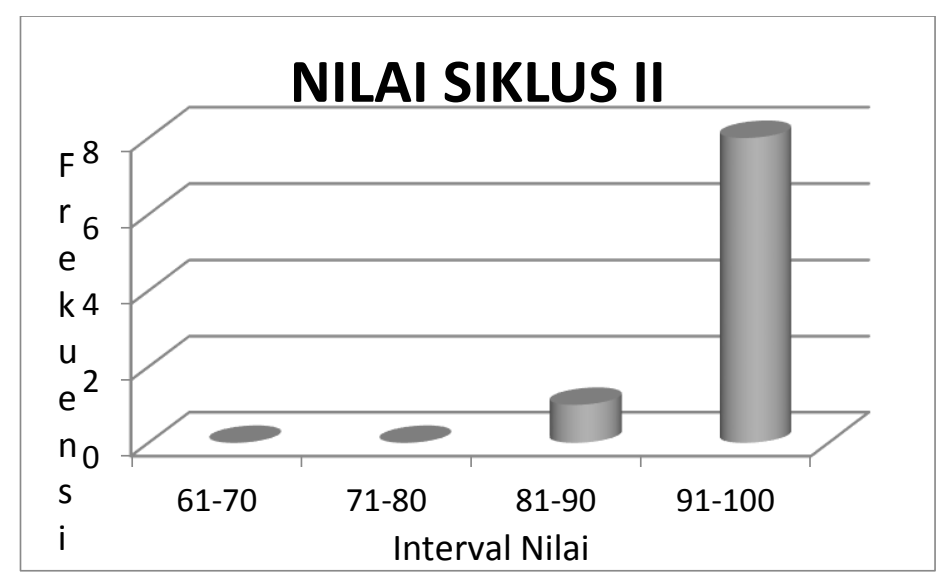

Gambar 3.Grafik Nilai Peningkatan Kompetensi guru Dalam Menyusun Silabus Pembelajaran Siklus II

Berdasarkan data yang diperoleh dari siklus II dapat dikatakan bahwa terjadi peningkatan untuk masing-masing indikator. Data dari pra siklus, siklus I, dan siklus II dapat diketahui bahwa setiap siklus mengalami peningkatan untuk masing-masing indikator komponen pelaksanaan Silabus Pembelajaran yaitu sebesar $75 \%$. Dan dari data akhir yang diperoleh dari siklus II rata-rata persentase kompetensi guru dalam menyusun Silabus Pembelajaran di SD Negeri 1 Kalinanas adalah 99 dengan persentase $99 \%$ sudah memenuhi indikator keberhasilan yaitu sebesar $75 \%$. Untuk lebih jelasnya dapat dilihat pada tabel 4.

Tabel 4.Perbandingan Ketuntasan Pra Siklus, Siklus I Dan Siklus II

\begin{tabular}{lccc}
\hline $\begin{array}{l}\text { INTERVAL } \\
\text { NILAI }\end{array}$ & $\begin{array}{c}\text { PRA } \\
\text { SIKLUS }\end{array}$ & $\begin{array}{c}\text { SIKLUS } \\
1\end{array}$ & $\begin{array}{c}\text { SIKLUS } \\
\text { II }\end{array}$ \\
\hline $61-70$ & 3 & 1 & 0 \\
\hline $71-80$ & 1 & 2 & 0 \\
\hline $81-90$ & 5 & 5 & 1 \\
\hline $91-100$ & 0 & 1 & 8 \\
\hline
\end{tabular}

Berdasarkan tabel 4. di atas maka dapat digambarkan ke dalam grafik seperti di bawah ini :

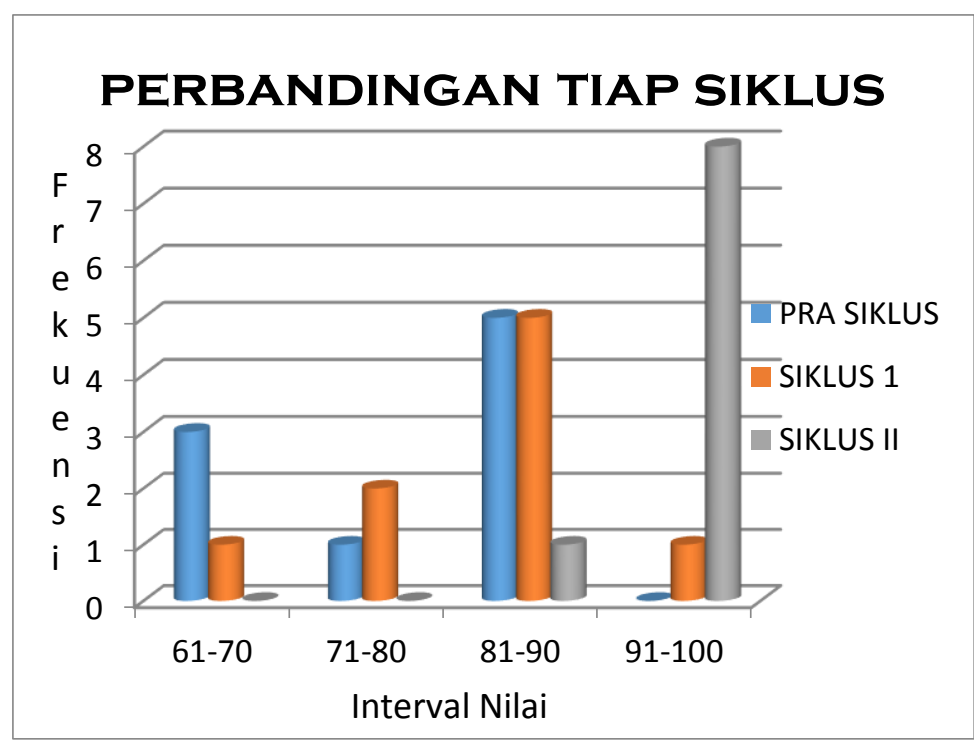

Gambar 4. Grafik Perbandingan Ketuntasan Pra Siklus, Siklus I Dan Siklus II 
Dari data yang diperoleh dari pra siklus, siklus I, dan siklus II dapat disimpulkan bahwa terjadi peningkatan kompetensi guru dalam menyusun Silabus Pembelajaran di SD Negeri 1 Kalinanas pada tahun 2016/2017. Hal ini dikarenakan penggunaan bimbingan dan supervisi yang dilakukan oleh Kepala Sekolah terhadap para guru.

\section{Kesimpulan}

Berdasarkan hasil Penelitian Tindakan Sekolah (PTS) dapat disimpulkan bahwa bimbingan dan supervisi dapat meningkatkan motivasi guru dalam menyusun Silabus Pembelajaran dengan lengkap. Guru menunjukkan keseriusan dalam memahami dan menyusun Silabus Pembelajaran apalagi setelah mendapatkan bimbingan pengembangan/ penyusunan Silabus Pembelajaran dari peneliti. Informasi ini peneliti peroleh dari hasil pengamatan pada saat mengadakan wawancara dan bimbingan pelaksanaan Silabus Pembelajaran kepada para guru. Bimbingan dan supervisi dapat meningkatkan kompetensi guru dalam menyusun Silabus Pembelajaran. Hal itu dapat dibuktikan dari hasil observasi /pengamatan yang memperlihatkan bahwa terjadi peningkatan kompetensi guru dalam menyusun Silabus Pembelajaran dari pra siklus ke siklus II . Pada pra siklus nilai rata-rata komponen Silabus Pembelajaran adalah 77 dengan persentase 52\%, siklus I nilai rata-rata komponen Silabus Pembelajaran adalah 84 dengan persentase $67 \%$ dan pada siklus II 98 dengan persentase 95\%. Jadi, terjadi peningkatan dari masing-masing siklus dan pada tiaptiap indikator.

\section{Referensi}

[1] Depdiknas. 2003. UU RI No. 20 Tahun 2003 tentang Sistem Pendidikan Nasional. Jakarta: Depdiknas.

[2] Kimball, Wiles.1976. Introduction to Educational Administration Boston. Allyn and Baccon, Inc

[3] Suparlan. 2005. Menjadi Guru Efektif. Yogyakarta: Hikayat Publishing.

[4] Tim Redaksi Kamus Besar Bahasa Indonesia. Edisi kedua 